\title{
Oil crystallization properties as an index for monitoring early stage curing of oil-based paints: DSC analysis on linseed oil systems
}

\author{
Silvia Pizzimenti ${ }^{1} \cdot$ Francesca Saitta $^{1} \cdot$ Marco Signorelli $^{2} \cdot$ Maria Rosaria Tinè $^{2} \cdot$ Ilaria Bonaduce $^{1} \cdot$ Celia Duce $^{1}$. \\ Dimitrios Fessas ${ }^{2}$ (D)
}

Received: 22 July 2021 / Accepted: 15 January 2022 / Published online: 21 February 2022

(c) The Author(s) 2022

\begin{abstract}
In this work, we propose to follow the crystallization capability of oils in oil-based paints, during curing, as an indirect index of the matrix status in the early stages of paint film formation that usually are indicative and crucial to understand the process evolution. To proof the concept, the oil crystallization properties were investigated through DSC measurements on samples of both unpigmented linseed oil and two model paints, composed by lead white + linseed oil (LWLO) and ultramarine blue + linseed oil (UBLO), at different ageing time at room and oxygen-limiting conditions. The results indicate that the curing process strongly affects the oil's ability of forming crystals in the paint layers, and the proposed experimental approach is rather suitable and sensitive enough to discriminate differences between the action of pigments and environmental conditions. On the other hand, despite the simplicity and the potentiality, this approach is limited at the early stages of paint curing offering an index of the overall matrix status and therefore must be intended as a complementary method that has to be integrated with other approaches if the aim is to explore in detail the chemical and physical aspects of the curing process.
\end{abstract}

Keywords Linseed oil · DSC · Oil paint curing · Lead white · Ultramarine blue

\section{Introduction}

Paints consist in general of pigment particles dispersed in a liquid binder [1]. The function of the binder in paints is to bind the pigment in a rigid film [1] after "drying", considering that such a term is used for any process (solvent evaporation, crosslinking, etc.) that leads the system to this final state.

Traditional oil paints are characterized by the use of a drying oil as a binder. Drying oils are liquid oils at room temperature composed by triglycerides, the majority of

Silvia Pizzimenti and Francesca Saitta are contributed equally to the work.

Celia Duce

celia.duce@unipi.it

Dimitrios Fessas

dimitrios.fessas@unimi.it

1 Dipartimento di Chimica e Chimica Industriale, Università di Pisa, Via Moruzzi 13, 56124 Pisa, Italy

2 DeFENS, Università degli Studi di Milano, Via Celoria 2, 20133 Milano, Italy which are formed by polyunsaturated acyl chains. Traditionally, the most used drying oil is linseed oil, whose main fatty acids are linolenic acid (48-60\%), linoleic acid (14-19\%), oleic acid (14-24\%), palmitic acid (6-7\%) and stearic acid (3-6\%) [2]. The curing mechanism of oil paints involves the autoxidation of unsaturated fatty acids via free radical chain reactions [3-5].

Differential scanning calorimetry (DSC) has been widely applied in the field of cultural heritage materials [6-8] and it is usually used to follow the curing of oil-based paints by monitoring the decomposition/recombination of the peroxides and other radicals, which occurs between 60 and $200{ }^{\circ} \mathrm{C}$ [9-13].

However, the thermal effects of phenomena involving other constituents present in the paint formulation (waxes, proteins, etc.) may overlap within the same temperature range. For instance, beeswax, the most used among natural waxes $[14,15]$ is characterized by a melting transition between 45 and $70{ }^{\circ} \mathrm{C}$ [16]. Similarly, proteins show an endothermic effect in the temperature range $60-90{ }^{\circ} \mathrm{C}$ due to conformational transitions and start to pyrolyze at around $200{ }^{\circ} \mathrm{C}[17,18]$. Furthermore, the peak of peroxides decomposition/recombination is observable after a certain 
time (one or more days of drying) depending on the pigment included into the paint and thus on the mechanism involved in the formation of the polymer network [19].

In this frame, we propose a complementary calorimetric method to monitor the curing process, with a more specific focus on the early stages that usually are indicative and crucial to obtain information on the process evolution. Specifically, dealing with oil-based paints, the oil crystallization properties may be exploited as an indirect index of the matrix status. Indeed, the amount of oil able to crystallize as well as the crystallization kinetics may be influenced by the matrix because of the network generated by the autoxidation reactions, thus decreasing the mobility of the molecules and hindering their crystallization. Based on this concept, the scope of this work was to apply the DSC technique to monitor the crystallization proprieties of oil in oil-based paints, assessing whether this observable property is sensitive enough to follow the early-stage progress of curing.

As a matter of fact, the DSC technique has been widely used to study, among other physicochemical proprieties, the crystallization and melting profiles of oils in complex matrices in the food research [20-30], allowing the detection of matrix effects on the oil crystallinity degree as well as on the oil crystals stability. Nonetheless, to our knowledge, no analogous application of the DSC technique on paint systems has been reported yet in the literature, and this work represents the first attempt to exploit such an approach for the monitoring of oil-paint curing.

The study was carried out on model paint systems comprising a simple mixture of linseed oil (a model drying oil $[1,2])$ and lead white $\left(2 \mathrm{PbCO}_{3} \cdot \mathrm{Pb}(\mathrm{OH})_{2}\right)$, that is a through dryer [31-33], or ultramarine blue $\left((\mathrm{NaCa})_{8}\left[\mathrm{Al}_{6} \mathrm{Si}_{6} \mathrm{O}_{24}\right]\right.$ $\left.\left(\mathrm{SO}_{4}, \mathrm{~S}, \mathrm{Cl}\right)_{2}\right)$, that is a slow dryer [1].

The monitoring of the crystallization properties of linseed oil was performed by running DSC cooling/heating cycles at different regular time intervals on samples which were left to age at indoor conditions. The results are here compared with those previously obtained by us on the same painting systems monitoring the DSC peroxides decomposition/recombination peak [19]. Through the investigation of the paint curing under limiting oxygen conditions, further details about the action of the pigments on linseed oil crystallization properties and hence on the whole curing process were evidenced.

\section{Materials and methods}

\section{Oil paints preparation}

Fresh linseed oil (purchased from Maimeri-Milan, Italy) was mixed with either lead white (Kremer pigmenteGermany) or ultramarine blue (Zecchi-Florence, Italy) to obtain oil model paints with pigment/oil ratio of 70:30 and 44:56, respectively. Linseed oil alone and the two pigmented oil paints were casted onto glass microscope slides producing model paintings of relatively uniform thickness. All samples were left to dry at non-controlled room conditions (exposed to air and at natural indoor day-night light). The oil paint layers were labelled as follows: LO for the unpigmented Linseed Oil; LWLO for Lead White + Linseed Oil paint; UBLO for Ultramarine Blue + Linseed Oil paint.

\section{Differential scanning calorimetry}

A DSC 2920 (TA Instrument, USA) calorimeter with stainless steel sealed pans was used and two cooling/heating from 25 to $-60{ }^{\circ} \mathrm{C}$ at $2{ }^{\circ} \mathrm{C} \mathrm{min}{ }^{-1}$ were performed to assess crystallization/melting properties of oil-based paints. An empty pan was used as reference and calibration was carried out with indium as standard. Samples were prepared by scratching the paint layer from the glass slides by means of a scalpel. In order to correlate the melting profiles of triacylglycerols crystals with the paint curing progress, besides the characterization of the fresh samples, linseed oil alone and oil paints were analysed at different ageing times, particularly after 24, 48, 72, 96 and $168 \mathrm{~h}$ of natural ageing. Moreover, additional DSC cooling/heating cycles were applied to the already sealed and scanned pans containing the $48 \mathrm{~h}$-aged samples, which were left to age further into the sealed pans (the same treatment was also applied to the sealed and scanned pans containing the $24 \mathrm{~h}$-aged LWLO sample for the sake of comparison, see below in the results section and in the Supplementary Material). These extra runs were performed at different regular times in order to investigate the effect of oxygen limitation given by the pan sealing on the paints' thermal behaviour.

Data analysis was performed with the dedicated software IFESTOS (assembled by one of the Authors according to [34] following procedures reported in previous studies [35]. 
In brief, the output signal in $\mathrm{mW}$ units was normalised by the oil mass of each sample, and the excess heat capacity $C_{\mathrm{P}}^{\mathrm{exc}}(T) / \mathrm{J} \mathrm{K}^{-1} \mathrm{~g}^{-1}$ oil mass, i.e. the difference between the apparent heat capacity $C_{\mathrm{P}}(T)$ of the sample and the heat capacity of the oil liquid state, was recorded across the scanned temperature range. Through this treatment, the area beneath the recorded peaks directly corresponds to the triacylglycerols' melting transition enthalpy, $\Delta_{\mathrm{m}} H$ (or to the crystallization enthalpy $\Delta_{\mathrm{c}} H$, if a cooling run is considered). In all cases, the transitions were completely reversible, hence no differences in the enthalpic contribution and the curve profiles were observed over the two cooling/heating cycles applied (data not shown), meaning that the experimental duration of our measurements is shorter than the time required by the ongoing process (autoxidation of unsaturated fatty acids) to produce observable effects on the curve. Three replicates were performed for each model paint layer.

\section{Results and discussion}

\section{Crystallization properties of linseed oil-based model paint layers}

Figure 1 reports the DSC melting profiles of the crystals formed during the first cooling run (from 25 to $-60{ }^{\circ} \mathrm{C}$ at $2{ }^{\circ} \mathrm{C} \mathrm{min}^{-1}$ ) in the unpigmented linseed oil (LO) and in fresh model paints prepared as lead white + linseed oil (LWLO) and ultramarine blue + linseed oil (UBLO).

As far as the unpigmented linseed oil is concerned (orange trace in Fig. 1), we observe a complex endothermic signal that reveals the melting of several triacylglycerols'

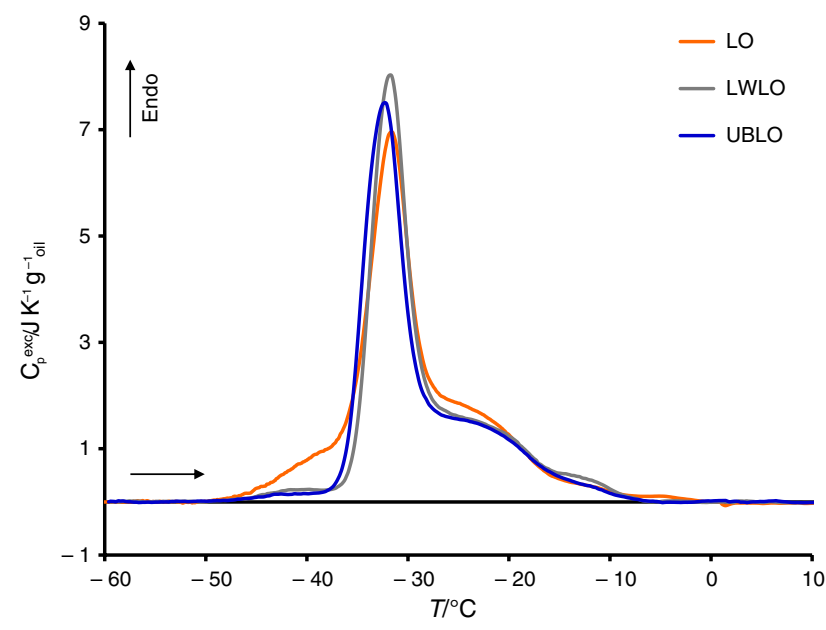

Fig. 1 DSC curves of LO (unpigmented Linseed Oil, orange trace), LWLO (Lead White + Linseed Oil, grey trace) and UBLO (Ultramarine Blue, blue trace) fresh model paints at $t=0$ polymorphic crystals with different stabilities, in agreement with the published literature $[36,37]$. The main calorimetric contribution is centred at $T \approx-31{ }^{\circ} \mathrm{C}$ and is due to the melting of oil crystals organized as hexagonal cells ( $\alpha$ form) [37]. The shoulder at $T \approx-40{ }^{\circ} \mathrm{C}$ is ascribable to the melting of low stability $\alpha$ form crystals of unsaturated triacylglycerols. The two shoulders at about -22 and $-11{ }^{\circ} \mathrm{C}$ can be, respectively, assigned to $\beta$ ' and $\beta$ crystalline forms, i.e. structures where triacylglycerols are organized as orthorhombic perpendicular cells $\left(\beta^{\prime}\right)$ and triclinic parallel cells $(\beta)$, which are likely formed by transformation of the metastable $\alpha$ form to the more stable $\beta$ form $[28,36,38]$.

In the DSC traces of LWLO and UBLO fresh model paints (Fig. 1 as grey and blue traces, respectively) we observe that both profiles are quite similar to the reference LO curve. The only significant difference is observed in the first shoulder that appears significantly reduced.

Considering that lipolysis, autoxidation and photooxidation influence the DSC profiles [30], while the presence of pigments did not significantly affect most of the two melting profiles, we may argue that autoxidation chain reactions, that are the basis of the polymer network formation, have not occurred yet to a significant extent in the case of fresh paints. Indeed, considering the different chemistry of lead white and ultramarine blue on linseed oil curing process, we would expect differences on the kinetics of the formation of the polymer network [19] (see below for more details), and in turn differences in LWLO and UBLO overall curves. Instead, the curves shown in Fig. 1 suggest that the disappearance of the first shoulder from the crystal melting profiles may be due to some other reasons that recall physical effects. In other words, we may argue that the lack of the least stable crystal forms in the pigmented systems is may be due either to the viscous environment formed in the presence of pigments that reduces and/or inhibits their formation or to a mere matter of steric hindrance caused by the pigment particles that prevent the correct formation of those crystals.

In any case, the kinetics of the crystallization process depends on the cooling rate and on potential annealing procedures that may result in a different amount of crystal formation according to the experimental procedure. In our case, the cooling procedure applied was always kept the same for all systems and the parameters' values obtained for the LO, LWLO and UBLO systems at $t=0$ have only been considered as the respective relative reference points. In other words, we assume that the overall enthalpies observed at $t=0$, namely $\Delta_{m} H=(63 \pm 3) \mathrm{J} \mathrm{g}^{-1}$ oil for $\mathrm{LO}, \Delta_{m} H=(57 \pm 3)$ $\mathrm{J} \mathrm{g}^{-1}$ oil for LWLO and $\Delta_{m} H=(56 \pm 3) \mathrm{J} \mathrm{g}^{-1}$ oil for UBLO, are the reference values representing the maximum amount of crystallizable oil in our conditions.

The influence of the advancement of the curing process up to one week on the crystallization peak of linseed oil is 
Fig. 2 DSC curves of linseed oil melting in LO, LWLO and UBLO model paint layers at different time of curing under natural indoor conditions. Detailed thermograms are reported in the Supplementary Material

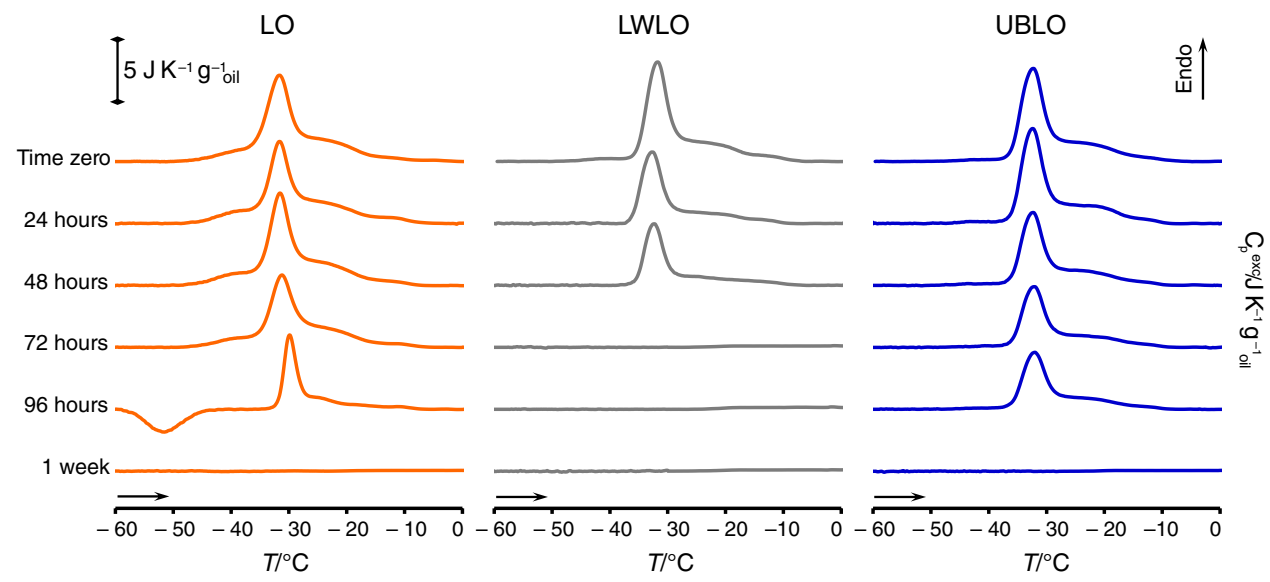

Despite the decrease in the melting enthalpies, we observe that the profiles of the curves remain similar, indicating that same type of crystals is always present. This indicates that the crystallization mechanisms remain unaffected by the advancing curing, and the only observable effect is a decrease in the number of molecules which can crystallize. Indeed, when the paint layer is exposed to air, chemical reactions are triggered and lead to a polymer network ("paint curing"). As already mentioned before, the curing of paint layers based on drying oils, such as linseed oil, occurs through autoxidative processes starting with the formation of the radical $R$. after the abstraction of a hydrogen atom from an unsaturated fatty acid RH. Briefly, once the radical $R$. is formed, propagation begins with oxygen addition to form a peroxyl radical ROO- which abstracts hydrogens from nearby $\mathrm{R}^{\prime} \mathrm{H}$ molecules to form a hydroperoxide $\mathrm{ROOH}$ as intermediate while generating a new radical $\left(R^{\prime} \cdot\right)$. Hydroperoxides may decompose to alkoxyl radicals $\mathrm{RO} \cdot$ and $\mathrm{OH} \cdot$, and RO- may abstract hydrogens from $R^{\prime \prime} H$ once again producing $R^{\prime \prime}$. Termination reactions between radicals lead to the polymer formation. Several other competitive reactions may occur, some of which still ultimately lead to the polymeric network, other to the formation of oxidation products [4, 5].

All these events, i.e. chemical modifications of triacylglycerols as well as the production of dimers and oligomers, may impair the strict order constraints required for the crystalline structure, hence reducing the amount of triacylglycerols available for crystal formation over time. Moreover, the remaining free oil is now in a modified environment with higher viscosity that makes the crystallization process more difficult from a kinetic point of view. In other words, 
reduction in the crystallinity degree observed, with respect to the reference at $t=0$, represents an indirect index of the matrix modification at the early-stage curing.

Furthermore, the trends of the crystallinity loss shown in Fig. 3 clearly indicate that this index may follow and quantify the different kinetics of the process occurred in the three systems in accordance with the literature. In particular, we observe that the presence of the pigments accelerates the loss of crystallinity, with LWLO being the most affected.

Indeed, according to the literature, in the case of LWLO the energy barrier for the formation of R- in the autoxidation chain reaction may be lowered by $\mathrm{Pb}^{2+}$ which acts as catalysts. In fact, lead is known to be an efficient through drier, i.e. an agent that catalyses the polymerization mechanism [31]. It decreases the stability of the peroxides [19] and induces a quick conversion of $\mathrm{ROOH}$ into $\mathrm{RO} \cdot+\cdot \mathrm{OH}$, which generally is the rate-limiting step in the propagation steps [39]. Consequently, a rapid and full consumption of the fatty acids' double bonds takes place, promoting a better and uniform drying throughout the entire film thickness as well as the formation of a well-established polymeric network $[19,33]$.

On the other hand, the slower kinetics observed in the case of UBLO (Fig. 3) is also in line with the literature that reports that the drying in the presence of ultramarine blue is slower than with lead white [1,19]. Ultramarine blue stabilizes the peroxides [19] slowing down the curing process and favouring alternative reaction pathways competing with the formation of a stable crosslinked network [19]. The trend of peak enthalpy values obtained from the DSC monitoring of the peroxides decomposition/recombination (obtained under the experimental conditions of [38]) and that of crystal melting enthalpy values obtained from the DSC monitoring the oil crystallization at different time of curing under natural indoor conditions are compared for LWLO and UBLO in Fig. S3. We observe that the crystallization ability vanishes when the peroxide peak reaches a maximum in both painting systems. The overall picture indicates that the evolution of the degree of oil crystallinity well correlates with the phenomena taking place in the first stages of curing and is sensitive to the pigment present in the paint formulation.

\section{Monitoring of linseed oil-based model paint layers at oxygen-limiting conditions}

Following the same experimental approach, we evaluated the early-stage paint curing in oxygen-limiting conditions. Indeed, the addition of oxygen is crucial for the beginning of the autoxidation process and has a fundamental role also at later stages when other competitive phenomena might establish. More specifically, we selected as a starting point samples aged for $48 \mathrm{~h}$ at room conditions, i.e. samples in which the curing process was already established, as visible in Fig. 3. The samples were kept in the sealed calorimetric pans at room temperature and underwent cooling/heating cycles at regular time intervals for a maximum of 19 weeks. The melting enthalpy and maximum temperature values obtained are reported in Fig. 4 together with the respective DSC profiles.

As far as LO is concerned (Fig. 4a-b), we observe that, after a small decrease observed up to 7 days, both the melting enthalpy and maximum temperature values remain substantially stable for 18 weeks. Such a stability is a strong indication that the curing does not progress because of the lack of oxygen.

A completely different scenario emerges in the case of LWLO. As shown in Fig. 4c-d, we observed a continuous decrease of the $\Delta_{\mathrm{m}} H$ values that reveals that the paint curing keeps going on, even though the rate of the process is considerably lower than the one exhibited in Fig. $2 b$ for curing at room conditions. This strongly indicates that lead mainly influences the polymerization steps without necessarily being directly involved in the step related to oxygen addition, in accordance with the literature [19]. Furthermore, we observe also a gradual upshift of the $T_{\max }$ values, which is a symptom of the modification of the crystals' surrounding environment, which may lead to crystals with different overall thermal stability [40]. This effect was not observable in Fig. 2, i.e. in the presence of air, where the overall process included oxygen capture and was too fast.

UBLO (Fig. 4e-f) shows a slow constant decrease of $\Delta_{\mathrm{m}} H$ values, which suggests that, though modifications in triacylglycerols' structure occur, the absence of oxygen significantly limits and/or slows down the paint curing, and, possibly, the reaction pathways [19]. The $T_{\max }$ values and the position of the DSC profiles with respect to the $x$-axis remain almost the same during the monitoring as observed for the unpigmented LO.

To sum up, we can observe completely different behaviours for LWLO and UBLO paint layers in oxygen-limiting conditions that highlight once again the different mechanisms involved during curing. However, if we compare the DSC profiles for such two paint layers at $48 \mathrm{~h}$ of indoor aging in Fig. 2, we may notice that the progression of the autoxidation reaction is much more advanced for LWLO at $48 \mathrm{~h}$ than for UBLO. For this reason, for the sake of comparison, the same monitoring was also carried out on pans containing LWLO which were sealed at $24 \mathrm{~h}$ of natural aging. Indeed, UBLO at $48 \mathrm{~h}$ and LWLO at $24 \mathrm{~h}$ of aging at room conditions are characterized by a similar starting $\Delta_{\mathrm{m}} H$ value of about $40 \mathrm{~J} \mathrm{~g} \mathrm{~g}^{-1}$ oil, and therefore may be considered as corresponding to an analogous degree of curing progress. The comparison is reported in Fig. S4 and leads to the same conclusions, that is, also in the absence of oxygen, curing in the presence of lead white progresses, although with a 
(a)

Time/weeks

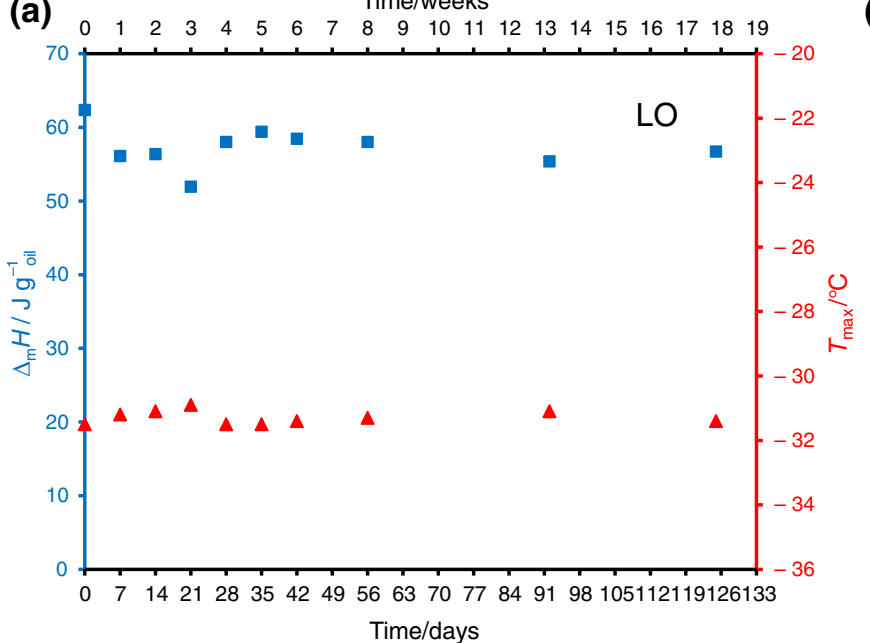

(c)

Time/weeks

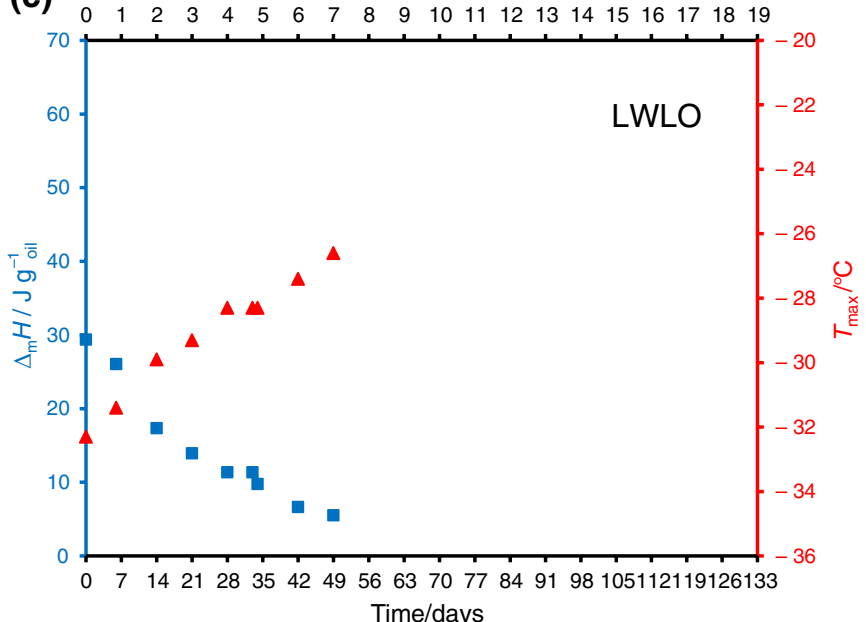

(e)

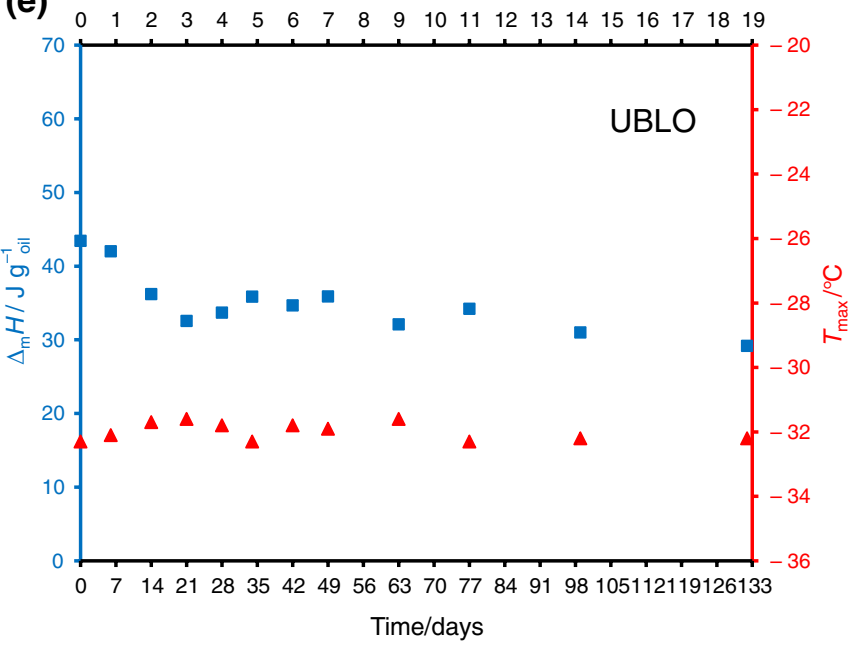

Fig. 4 Melting enthalpy (blue) and maximum temperature (red) values obtained from DSC monitoring on pans containing paint samples sealed at $48 \mathrm{~h}$ of natural curing for a LO, c LWLO and e UBLO. The corresponding DSC profiles are reported on the right side for $\mathbf{b} \mathrm{LO}, \mathbf{d}$ LWLO and $\mathbf{f}$ UBLO. The starting values at time 0 days correspond to
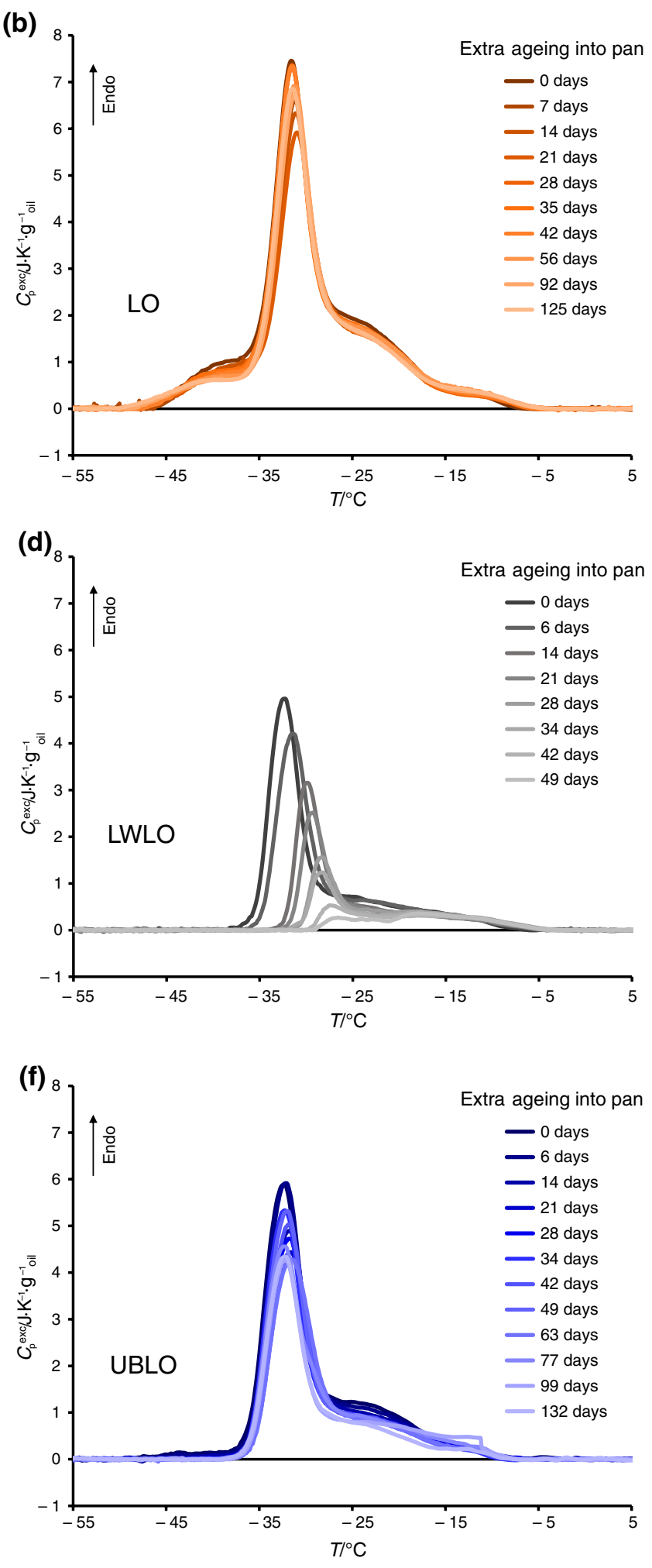

the parameters obtained from the DSC curves at $48 \mathrm{~h}$ of natural curing in Fig. 2, therefore the time in legends (panels $\mathbf{b}, \mathbf{d}, \mathbf{f}$ ) and $x$ axis (panels a, c, e) is intended as extra ageing into the pans (see Materials and methods section) 
lower rate. Further details and deeper chemical analysis and/ or interpretations are beyond the scope of this paper.

\section{Conclusions}

In this work, we follow the crystallization properties of oils in oil-based paints, through DSC cooling/heating cycles, to be proposed as an indirect index of the matrix status in the early stages of paint curing. For this purpose, the crystallization properties of unpigmented linseed oil and two model paints composed by lead white + linseed oil (LWLO) and ultramarine blue + linseed oil (UBLO) were investigated at different curing time, both at room and oxygen-limiting conditions.

The results indicate that the curing process strongly affects the oil's ability of forming crystals in the paint layers. The overall trend agreed with the literature data. In particular, even though the calculation of rate parameters is not simple to perform on these complex systems, whose mechanisms of network formation are based on radical reactions, the calorimetric profiles and the melting enthalpy data provide a phenomenological picture of the curing kinetics (e.g. qualitative time-dependence of the degree of crystallinity). On the other hand, the data obtained from measurements performed on closed pans, i.e. at limiting oxygen conditions, allow to gain indications on mechanistic effects of pigments on the polymer network formation, showing how each pigment type (through-dryer and slow-dryer) affects the curing process. To sum up, both the pigments accelerate the curing process, being lead white more efficient than ultramarine blue in aerobic conditions. On the other hand, only lead white catalyses the curing in oxygen-limiting conditions, although less effectively than when exposed to air.

In conclusion, the overall picture indicates that the proposed experimental approach is suitable for monitoring the early-stage progress of oil curing and is sensitive enough to discriminate differences between the action of different pigments and environmental conditions. On the other hand, despite its simplicity and potentiality, this approach is limited at the early stages of paint curing, offering an indirect index of the overall matrix status, and therefore must be intended as a complementary method that has to be integrated with other approaches if the aim is to explore detailed chemical aspects of the curing process, including the widely used DSC monitoring of the peroxide/hydroperoxide decomposition reaction.

Supplementary Information The online version contains supplementary material available at https://doi.org/10.1007/s10973-022-11227-5.

Open Access This article is licensed under a Creative Commons Attribution 4.0 International License, which permits use, sharing, adaptation, distribution and reproduction in any medium or format, as long as you give appropriate credit to the original author(s) and the source, provide a link to the Creative Commons licence, and indicate if changes were made. The images or other third party material in this article are included in the article's Creative Commons licence, unless indicated otherwise in a credit line to the material. If material is not included in the article's Creative Commons licence and your intended use is not permitted by statutory regulation or exceeds the permitted use, you will need to obtain permission directly from the copyright holder. To view a copy of this licence, visit http://creativecommons.org/licenses/by/4.0/.

\section{References}

1. Mayer R. Artist's handbook of materials and techniques: revised and updated. Viking Books; 1991.

2. Lazzari M, Chiantore O. Drying and oxidative degradation of linseed oil. Polym Degrad Stab. 1999;65(2):303-13. https://doi. org/10.1016/S0141-3910(99)00020-8.

3. Schaich K. Lipid oxidation: theoretical aspects. Bailey's industrial oil and fat products. 2005.

4. Bonaduce I, Duce C, Lluveras-Tenorio A, Lee J, Ormsby B, Burnstock A, et al. Conservation issues of modern oil paintings: a molecular model on paint curing. Acc Chem Res. 2019;52(12):3397-406. https://doi.org/10.1021/acs.accounts. $9 \mathrm{~b} 00296$.

5. Honzíček J. Curing of air-drying paints: a critical review. Ind Eng Chem Res. 2019;58(28):12485-505. https://doi.org/10.1021/acs. iecr.9b02567.

6. Fessas D, Signorelli M, Schiraldi A, Kennedy CJ, Wess TJ, Hassel B, et al. Thermal analysis on parchments I: DSC and TGA combined approach for heat damage assessment. Thermochim Acta. 2006;447(1):30-5. https://doi.org/10.1016/j.tca.2006.04.007.

7. Fessas D, Schiraldi A, Tenni R, Zuccarello LV, Bairati A, Facchini A. Calorimetric, biochemical and morphological investigations to validate a restoration method of fire injured ancient parchment. Thermochim Acta. 2000;348(1-2):129-37. https://doi.org/10. 1016/S0040-6031(00)00350-6.

8. Saitta F, Signorelli M, Bramanti E, Pizzimenti S, Pelosi C, Duce $\mathrm{C}$, et al. DSC on ovalbumin-hematite "tempera" paints: The role of water and pigment on protein stability. Thermochim Acta. 2020;694: 178780. https://doi.org/10.1016/j.tca.2020.178780.

9. Mallégol J, Gonon L, Commereuc S, Verney V. Thermal (DSC) and chemical (iodometric titration) methods for peroxides measurements in order to monitor drying extent of alkyd resins. Prog Org Coat. 2001;41(1):171-6. https://doi.org/10.1016/S03009440(01)00144-8.

10. Ouldmetidji Y, Gonon L, Commereuc S, Verney V. A differential scanning calorimetry method to study polymer photoperoxidation. Polym Testing. 2001;20(7):765-8. https://doi.org/10.1016/S01429418(01)00024-1.

11. Izzo FC, Zendri E, Biscontin G, Balliana E. TG-DSC analysis applied to contemporary oil paints. J Therm Anal Calorim. 2011;104(2):541-6. https://doi.org/10.1007/ s10973-011-1468-y.

12. Duce C, Bernazzani L, Bramanti E, Spepi A, Colombini M, Tiné M. Alkyd artists' paints: Do pigments affect the stability of the resin? A TG and DSC study on fast-drying oil colours. Polym Degrad Stab. 2014;105:48-58. https://doi.org/10.1016/j.polym degradstab.2014.03.035.

13. Tamburini D, Sardi D, Spepi A, Duce C, Tinè MR, Colombini MP, et al. An investigation into the curing of urushi and tung oil films 
by thermoanalytical and mass spectrometric techniques. Polym Degrad Stab. 2016;134:251-64. https://doi.org/10.1016/j.polym degradstab.2016.10.015.

14. Izzo FC, van den Berg KJ, van Keulen H, Ferriani B, Zendri E. Modern oil paints-formulations, organic additives and degradation: some case studies. Issues in contemporary oil paint. Cham: Springer; 2014. p. 75-104.

15. Wijnberg L. Do we see what we know or do we know what we see? Conservation of oil paintings in the Stedelijk Museum Amsterdam. Issues in contemporary oil paint. Cham: Springer; 2014. p. 21-32.

16. Ruguo Z, Hua Z, Hong Z, Ying F, Kun L, Wenwen Z. Thermal analysis of four insect waxes based on differential scanning calorimetry (DSC). Proc Eng. 2011;18:101-6. https://doi.org/10. 1016/j.proeng.2011.11.016.

17. Cordobés F, Partal P, Guerrero A. Rheology and microstructure of heat-induced egg yolk gels. Rheol Acta. 2004;43(2):184-95. https://doi.org/10.1016/j.foodhyd.2018.07.045.

18. Orsini S, Parlanti F, Bonaduce I. Analytical pyrolysis of proteins in samples from artistic and archaeological objects. J Anal Appl Pyrol. 2017;124:643-57.

19. Pizzimenti S, Bernazzani L, Tinè MR, Treil V, Duce C, Bonaduce I. Oxidation and cross-linking in the curing of air-drying artists' oil paints. ACS Appl Polym Mater. 2021. https://doi.org/10.1021/ acsapm.0c01441.

20. Kaisersberger E. DSC investigations of the thermal characterization of edible fats and oils. Thermochim Acta. 1989;151:83-90. https://doi.org/10.1016/0040-6031(89)85339-0.

21. Tan C, Che MY. Differential scanning calorimetric analysis of edible oils: comparison of thermal properties and chemical composition. J Am Oil Chem Soc. 2000;77(2):143-55. https://doi.org/ 10.1007/s11746-000-0024-6.

22. Chiavaro E. Differential scanning calorimetry: applications in fat and oil technology. Boca Raton: CRC Press; 2014.

23. Litwinienko G, Kasprzycka-Guttman T, Jarosz-Jarszewska M. Dynamic and isothermal DSC investigation of the kinetics of thermooxidative decomposition of some edible oils. J Therm Anal Calorim. 1995;45(4):741-50. https://doi.org/10.1007/BF025 48890.

24. Gloria H, Aguilera JM. Assessment of the quality of heated oils by differential scanning calorimetry. J Agric Food Chem. 1998;46(4):1363-8. https://doi.org/10.1021/jf9703664.

25. Litwinienko G, Kasprzycka-Guttman T. A DSC study on thermoxidation kinetics of mustard oil. Thermochim acta. 1998;319(1-2):185-91. https://doi.org/10.1016/S00406031(98)00410-9.

26. Litwinienko G. Autooxidation of unsaturated fatty acids and their esters. J Therm Anal Calorim. 2001;65(2):639-46. https://doi.org/ 10.1023/a:1017974313294.
27. Vittadini E, Lee J, Frega N, Min DB, Vodovotz Y. DSC determination of thermally oxidized olive oil. J Am Oil Chem Soc. 2003;80(6):533-7. https://doi.org/10.1007/s11746-003-0733-x.

28. Zhang Z-S, Li D, Zhang L-X, Liu Y-l. Heating effect on the DSC melting curve of flaxseed oil. J Therm Anal Calorim. 2014;115(3):2129-35. https://doi.org/10.1007/ s10973-013-3270-5.

29. Schiraldi A, Fessas D. Calorimetry and thermal analysis in food science. J Therm Anal Calorim. 2019;138(4):2721-32. https://doi. org/10.1007/s10973-019-08166-z.

30. Vecchio Ciprioti S, Paciulli M, Chiavaro E. Application of different thermal analysis techniques to characterize oxidized olive oils. Euro J Lipid Sci Technol. 2017;119(1):1600074.

31. Tumosa CS, Mecklenburg MF. The influence of lead ions on the drying of oils. Stud Conserv. 2005;50(sup1):39-47. https://doi. org/10.1179/sic.2005.50.Supplement-1.39.

32. White R, Thomas P, Phillips M, Wuhrer R. A DSC study of the effect of lead pigments on the drying of cold pressed linseed oil. J Therm Anal Calorim. 2005;80(1):237-9. https://doi.org/10.1007/ s10973-005-0642-5.

33. Soucek M, Khattab T, Wu J. Review of autoxidation and driers. Prog Org Coat. 2012;73(4):435-54. https://doi.org/10.1016/j. porgcoat.2011.08.021.

34. Barone G, Del Vecchio P, Fessas D, Giancola C, Graziano G. The deconvolution of multi-state transition DSC curves of biological macromolecules: bovine serum albumin and bovine seminal ribonuclease. Thermochim Acta. 1993;227:185-95. https://doi. org/10.1016/0040-6031(93)80261-8.

35. Aktas AB, Alamprese C, Fessas D, Ozen B. IR spectroscopy and chemometrics for physical property prediction of structured lipids produced by interesterification of beef tallow. LWT. 2019;110:2531. https://doi.org/10.1016/j.1wt.2019.04.057.

36. Chapman D. The polymorphism of glycerides. Chem Rev. 1962;62(5):433-56.

37. Hernqvist L. Polymorphism of triglycerides a crystallographic review. Food Struct. 1990;9(1):5. https://digitalcommons.usu.edu/ foodmicrostructure/vol9/iss1/5.

38. Oomah BD, Sitter L. Characteristics of flaxseed hull oil. Food Chem. 2009;114(2):623-8. https://doi.org/10.1016/j.foodchem. 2008.09.096.

39. Kamal-Eldin A, Pokorný J. Analysis of lipid oxidation. AOCS Press Champaign; 2005.

40. Alamprese C, Cappa C, Ratti S, Limbo S, Signorelli M, Fessas D, et al. Shelf life extension of whole-wheat breadsticks: Formulation and packaging strategies. Food Chem. 2017;230:532-9. https:// doi.org/10.1016/j.foodchem.2017.03.092.

Publisher's Note Springer Nature remains neutral with regard to jurisdictional claims in published maps and institutional affiliations. 